\title{
Evidence for a direct effect on articular cartilage and its lysosomal enzymes in filipin-induced arthritis
}

\author{
K. D. MUIRDEN AND MARGARET PHILLIPS \\ University of Melbourne Department of Medicine, The Royal Melbourne Hospital, Victoria 3050, Australia
}

It was suggested by Dingle (1962) that lysosomal enzymes might be responsible for damage to cartilage matrix in rheumatoid arthritis. Since then indirect evidence has linked lysosomal hydrolases with tissue damage in this disease. For example, Fell and Dingle (1963) showed that cathepsin D could degrade the protein-polysaccharide complex of cartilage ground substance leading to loss of metachromasia. This histochemical change can occur within a few weeks of the onset of rheumatoid arthritis (Janis and Hamerman, 1969). In another experiment, a striking loss of metachromasia occurred when cartilage fragments were incubated with cells from rheumatoid synovia (Hamerman, Janis, and Smith, 1967).

Increased levels of extractable acid phosphatase, $\beta$-acetyl glucosaminidase, and cathepsin $\mathrm{D}$ have been demonstrated in rheumatoid synovial tissue (Luscombe, 1963; Wegelius, Klockars, and Vainio, 1968; Muirden, 1972) and in cell-free synovial fluid (Jacox and Feldman, 1955; Smith and Hamerman, 1962; Caygill and Pitkeathly, 1966; Bartholomew, 1968). Evidence suggests that these enzymes in synovial fluid originate mainly from synovial lining cells rather than from synovial fluid leucocytes (Bartholomew, 1968; Jasani, Katori, and Lewis, 1969; Muirden, 1972). Furthermore, a correlation has been demonstrated between the concentrations of two lysosomal enzymes in homogenates of excised rheumatoid synovial tissue and the joint damage noted by the surgeon at the time of synovectomy (Muirden, 1972). This suggested that enzymes responsible for cartilage damage (including cathepsin D) may have diffused from the synovial membrane into articular cartilage. However, as Page Thomas (1969) has noted, it would be unwise to assume that chondrocytes play no part in the excessive destruction of their own matrix.

In this study we describe the measurement of lysosomal enzyme concentrations in articular cartilage and comparisons with synovial membrane enzyme activities in the same joint. This has been difficult to achieve in rheumatoid joints and the results of such studies will be published later. We now describe enzyme concentrations from synovia and articular cartilage in an experimental arthritis induced by intra-articular injections of the polyene antibiotic filipin into rabbit knee joints. Filipin has a molecular weight of 655 and its proposed structure indicates that it has a low charge (Weissman and Sessa, 1967). There would seem to be little barrier to its ingress into cartilage. It is thought that filipin produces its effect by disrupting membranes of susceptible cells (Weissman, Pras, and Rosenberg, 1967). Histologically the joint lesions are characterized by a proliferative synovitis, pannus formation, and cartilage degeneration. We have extended these morphological observations by a study of the ultrastructure of involved cartilage in order to compare these findings with the rheumatoid state.

\section{Material and methods}

\section{(1) Induction of the experimental arthritis}

Eleven adult rabbits were given intra-articular injections of $500 \mathrm{mg}$. filipin in $1.0 \mathrm{ml}$. of a 1 per cent. solution of dimethyl sulphoxide (DMSO) in saline. Injections were made in the right knee and the left knee was left intact as the control. In a preliminary series using three rabbits, the vehicle alone was injected into the left knee. This produced no morphological change in cartilage but some areas of haemorrhage were noted in the synovium. It was decided that a normal joint would be more suitable for ultrastructural and biochemical comparisons. It was accepted that the introduction of the needle and vehicle could have an additional irritating effect on the joint, but that this would be small in comparison with the effect of filipin. Joints were injected on average every 5 days and between three and eleven injections were given over periods of 2 to 11 weeks. At intervals the animals were killed with an overdose of pentothal and both knee joints quickly opened. Synovial tissue and articular cartilage for electron 
microscopy was placed immediately in fixative (phosphate-buffered glutaraldehyde). Small segments of tissue were fixed for $\mathbf{4 8} \mathrm{hrs}$ in phosphate-buffered formaldehyde for routine histology and the remaining synovium and articular cartilage kept unfixed for enzyme assays. Cartilage was frozen immediately in liquid nitrogen and synovial tissue stored frozen in $0.25 \mathrm{M}$ sucrose.

\section{(2) Processing of tissue for enzyme assay}

Synovial tissue was freeze thawed twice, then homogenized mechanically in a ground glass homogenizer. The homogenate suspended in $0.25 \mathrm{M}$ sucrose ( 10 per cent. w/v) was centrifuged at $20,000 \mathrm{G}$. for $50 \mathrm{~min}$. and the supernatant assayed for acid phosphatase (AP), $\beta$-acetyl glucosaminidase (AGA) and cathepsin D activity $(1 \mathrm{hr}$, $\frac{1}{2} \mathrm{hr}$, and 1 and $3 \mathrm{hr}$ incubations respectively). The frozen cartilage was ground to powder at the temperature of liquid nitrogen, suspended in $0.25 \mathrm{M}$ sucrose, and stood in the cold for $\frac{1}{2} \mathrm{hr}$. The suspension was then centrifuged at $20,000 \mathrm{G}$. for $20 \mathrm{~min}$. and the supernatant assayed for AGA and cathepsin D activity ( 2 to 4 and $18 \mathrm{hr}$ incubations respectively).

\section{(3) Enzyme assays}

The methods used for estimating AP and AGA have been recently recorded (Muirden, 1972). Cathepsin D was assayed by the method of Woessner and Brewer (1963). The haemoglobin substrate was denatured by incubation in $.05 \mathrm{M}$ citrate buffer, $\mathrm{pH} 3.5$ for $2 \mathrm{hrs}$ at $37^{\circ} \mathrm{C}$.
(4) Assay of DNA content

The sediment was dissolved in perchloric acid and DNA estimated by the indole method (Ceriotti, 1955).

\section{(5) Procedure for histology and electron microscopy}

Histological sections of synovial tissue were stained with haematoxylin and eosin and articular cartilage also with safranin 0 , counter-stained with fast green. Safranin 0 combines with the polyanions of cartilage and provides a quantitative histochemical method for following changes in concentration of mucopolysaccharides in cartilage ground substance (Rosenberg, 1971). Tissue retained for electron microscopy was post-fixed with osmium and stained with uranyl acetate or lead citrate, and sections from araldite-embedded blocks were examined in a Hitachi 11A electron microscope.

\section{Results}

The rabbit's right knee became swollen within 24 hrs of the first injection and remained unchanged during the weeks of repeated injections. When the knee was opened the synovial membrane was found to be thickened and vascular. An increase of synovial fluid was noted, but swabs taken from the joints were always sterile when cultured. Histological examination revealed proliferation of synovial lining cells which occasionally took the form of a palisade of cells vertical to the surface. The synovial stroma was infiltrated with inflammatory cells, both poly-

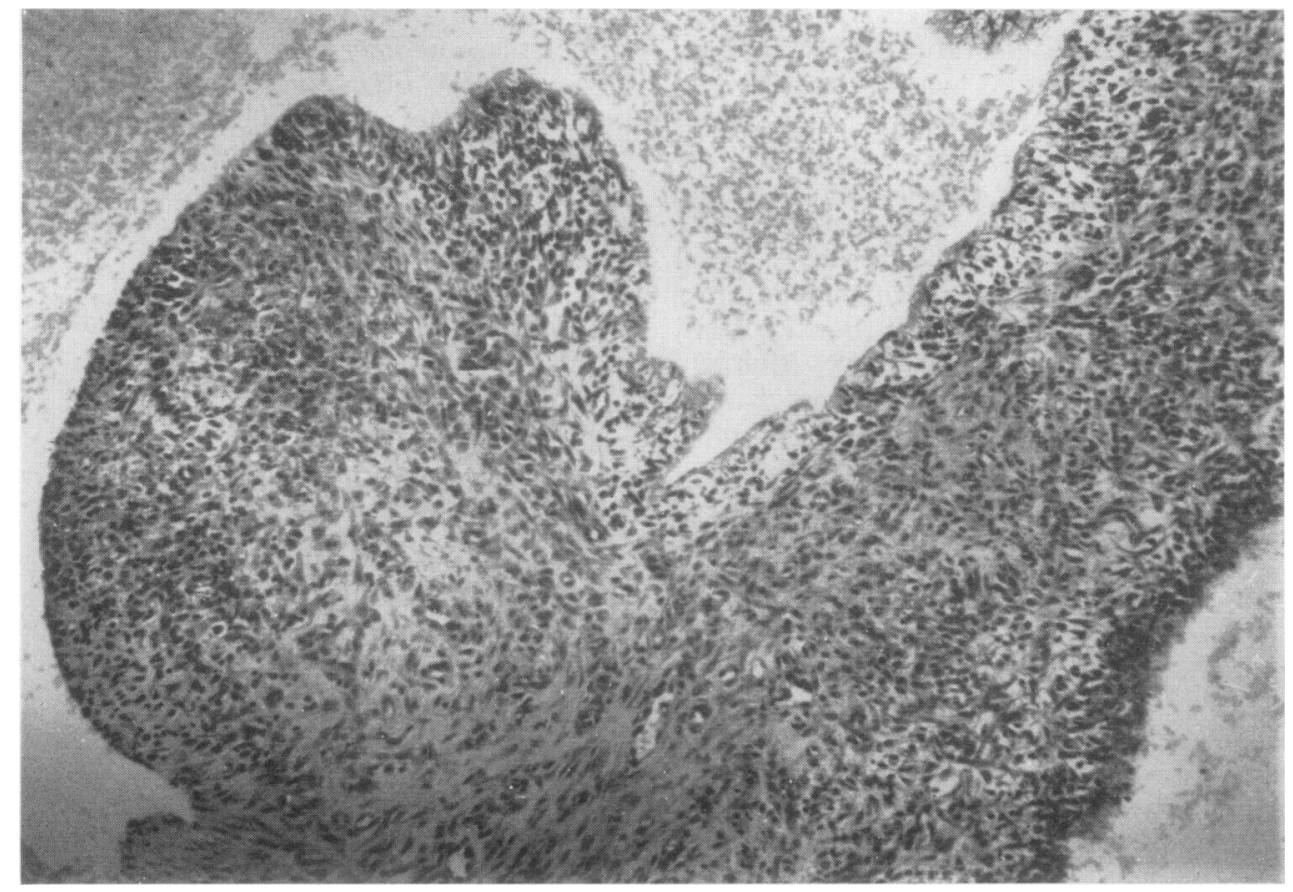

FIG. 1 Synovial membrane after nine filipin injections, showing lining cell proliferation and small round cell infiltration of stroma. Haematoxylin and eosin. $\times 140$ 


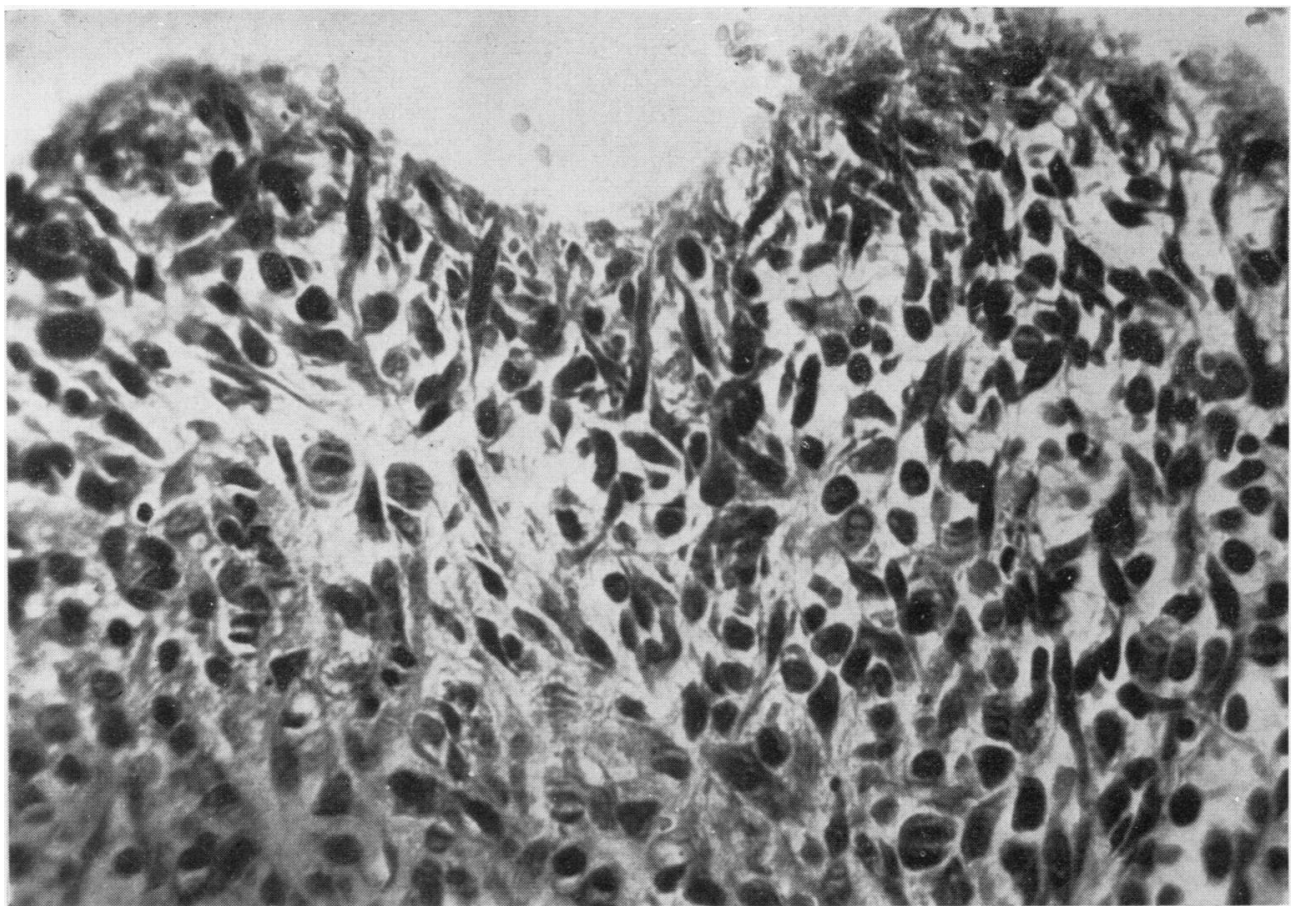

FIG. 2 Higher power view of surface area seen in Fig. 1. The lining cells are enlarged and arranged mainly perpendicular to the surface. Lymphocytes, plasma cells, and histiocytes are in the stroma. Haematoxylin and eosin. $\times 560$

morphonuclear leucocytes and lymphocytes. Occasional plasma cells were noted but lymphoid follicles were not seen (Figs 1 and 2). The stroma also contained large numbers of histiocytes similar in form to lining cells. In animals injected for several weeks pannus formation was evident and bony erosions were noted where the synovium was reflected onto the femoral condyles.

The difference in control and treated articular cartilage can be seen in safranin 0 -stained sections (Figs 3 and 4). Staining was decreased or absent throughout the whole thickness of cartilage in animals receiving many injections. Clustering of chondrocytes and areas sparsely populated with cells were seen (Fig. 4, overleaf). Surface irregularity and mild fibrillation was also noted. One rabbit (who had received eight filipin injections) contrasted with the majority in showing no difference in metachromasia on the two sides. It was found that enzyme levels were no higher in the cartilage on the treated side than on the control side in this animal.

\section{Electron microscopy}

The proliferated Type B synovial membrane lining cells showed dilated endoplasmic reticulum and the Type A cells contained enlarged and dense lysosomes similar to the picture seen in rheumatoid arthritis (Fig. 5). A few cells showed marked membrane damage (Fig. 6). The articular cartilage in control

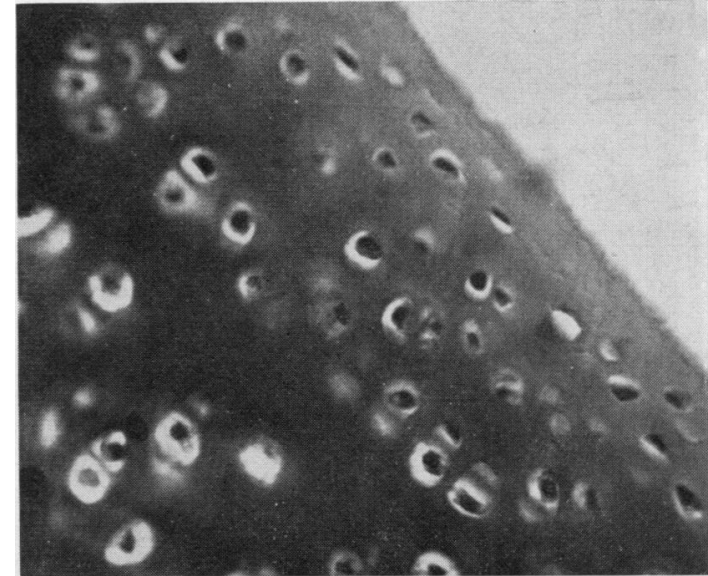

FIG. 3 Control articular cartilage with dense matrix staining. Sofranin $0 . \times 400$

animals showed a regular surface with chondrocytes in the surface area organized horizontally to the surface in the predominant orientation of collagen fibres (Fig. 7). Cells contained endoplasmic reticulum, Golgi zones, mitochondria, and frequently lipid droplets and perinuclear fibrillary material. Degenerative changes in these chondrocytes were not infrequent even in control cartilage. In the filipininjected joints, surface irregularity was evident and 
FIG. 4 Articular cartilage after three filipin injections, showing depletion of matrix staining and clumping of chondrocytes. Sofranin $0 . \times 500$

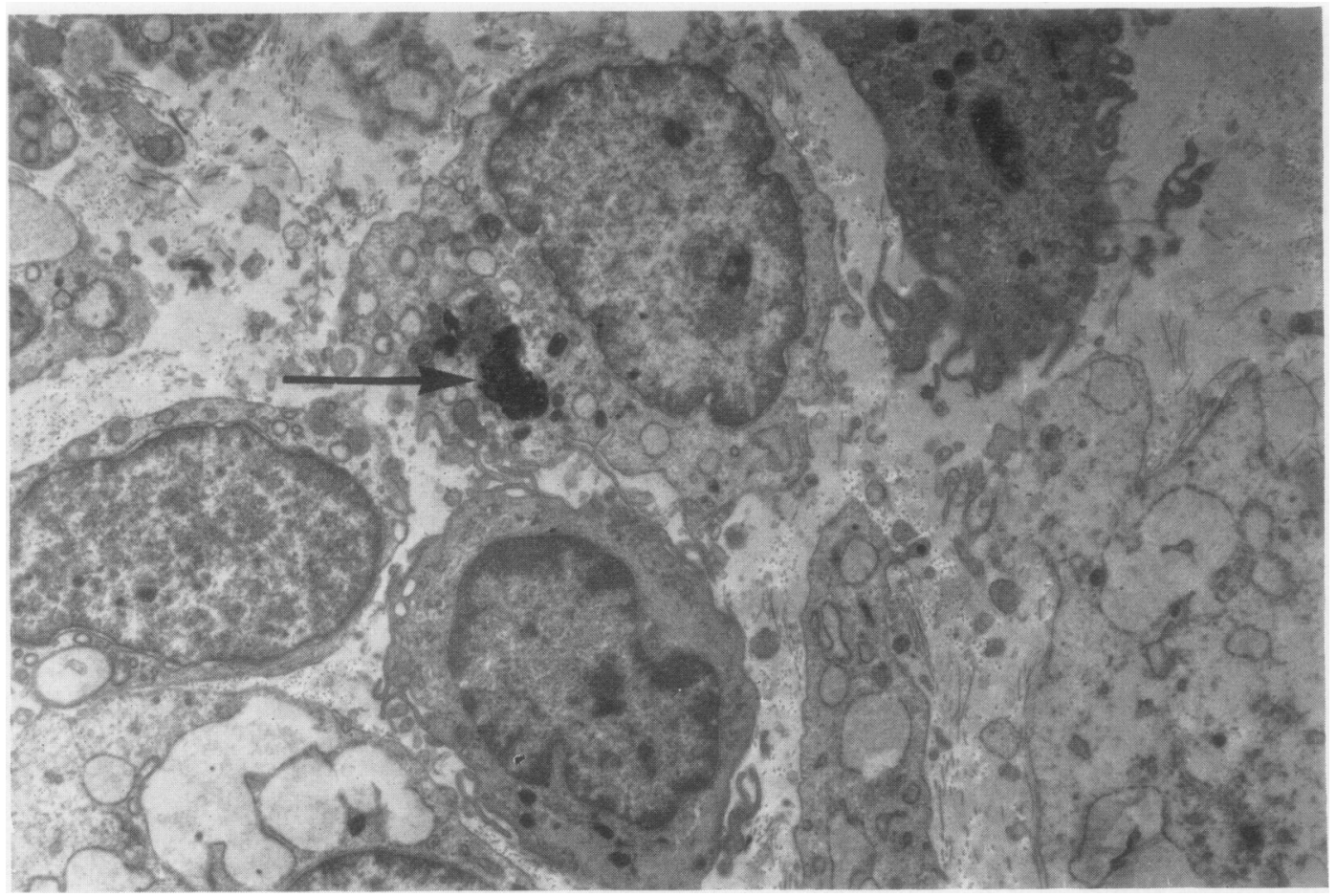

FIG. 5 Electron micrograph of synovial membrane (after eight filipin injections). Enlarged lysosomes are seen (arrow). Some of the other cells show dilated endoplasmic reticulum. $\times 12,500$

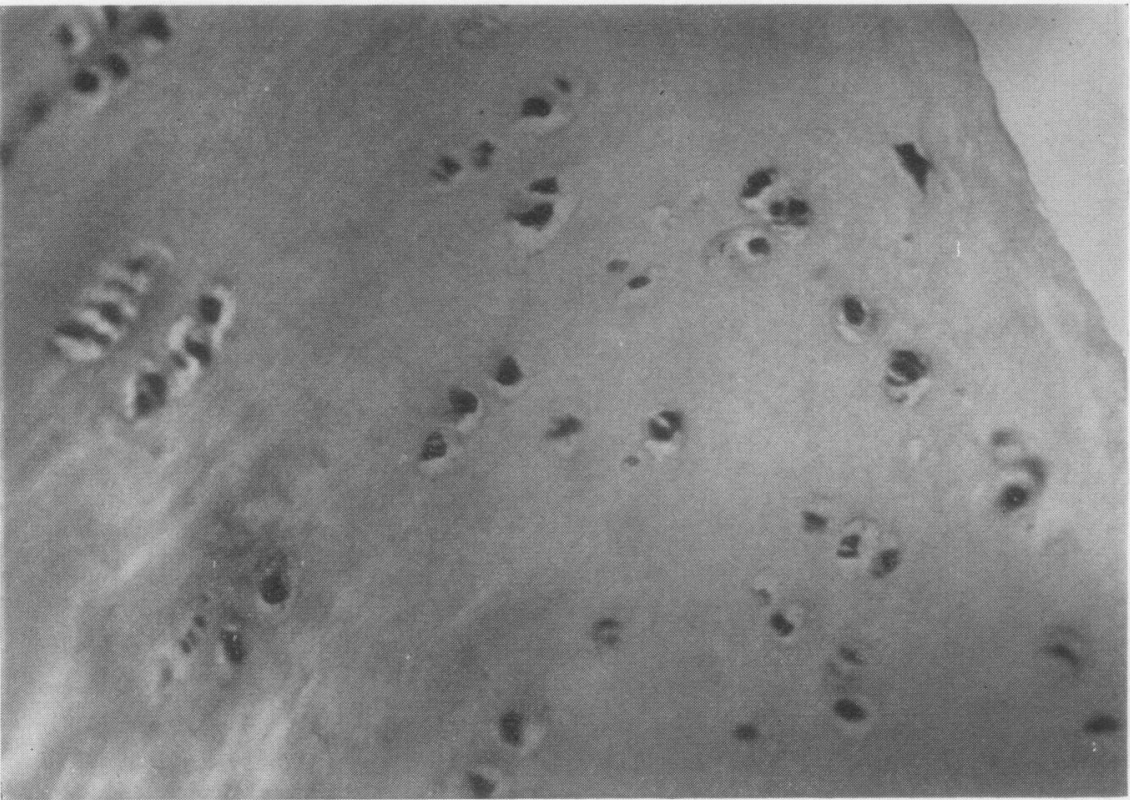




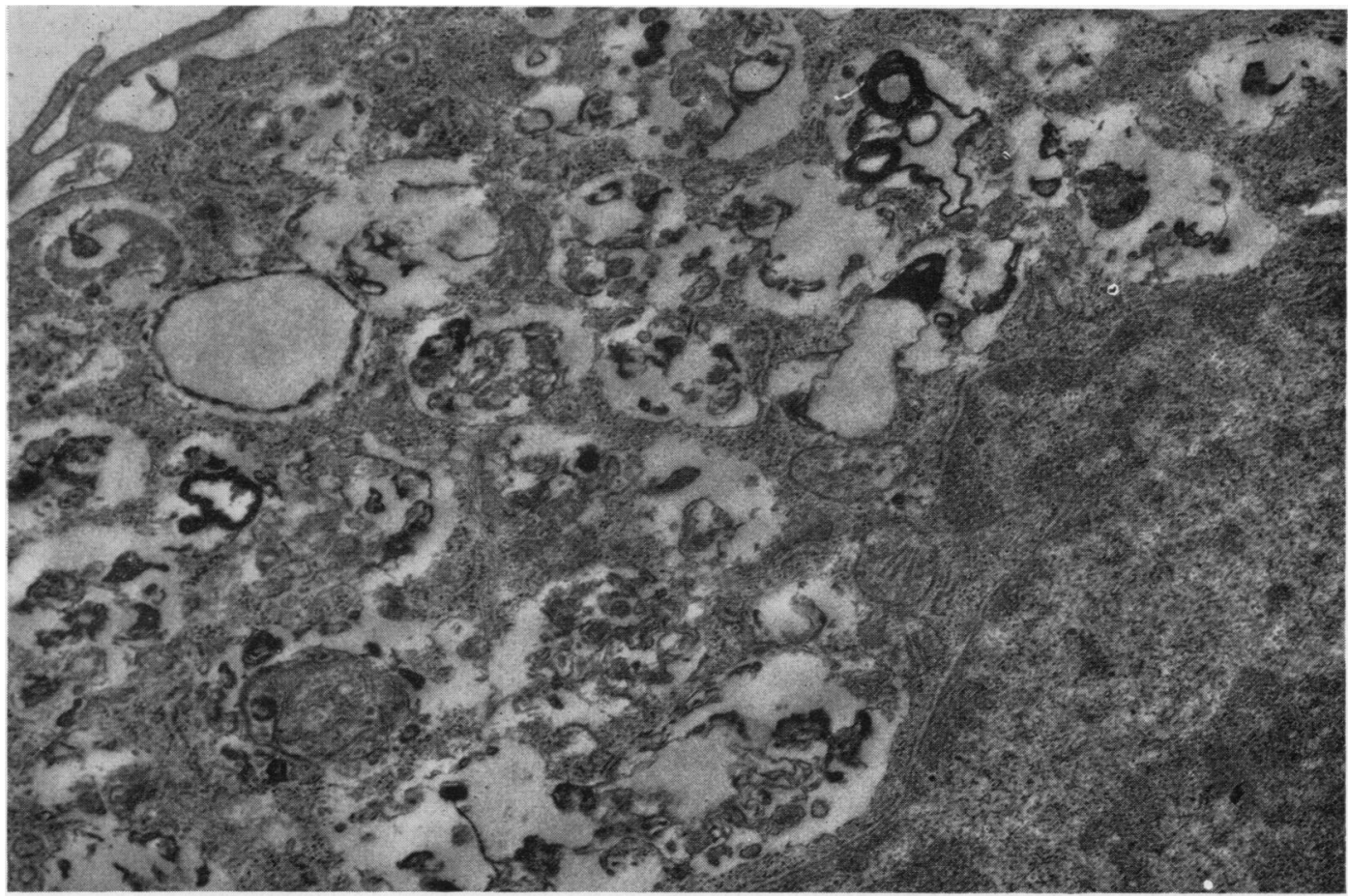

FIG. 6 Electron micrograph after eight filipin injections, showing Type A synovial cell, with abnormal cell membranes. $\times 27,500$

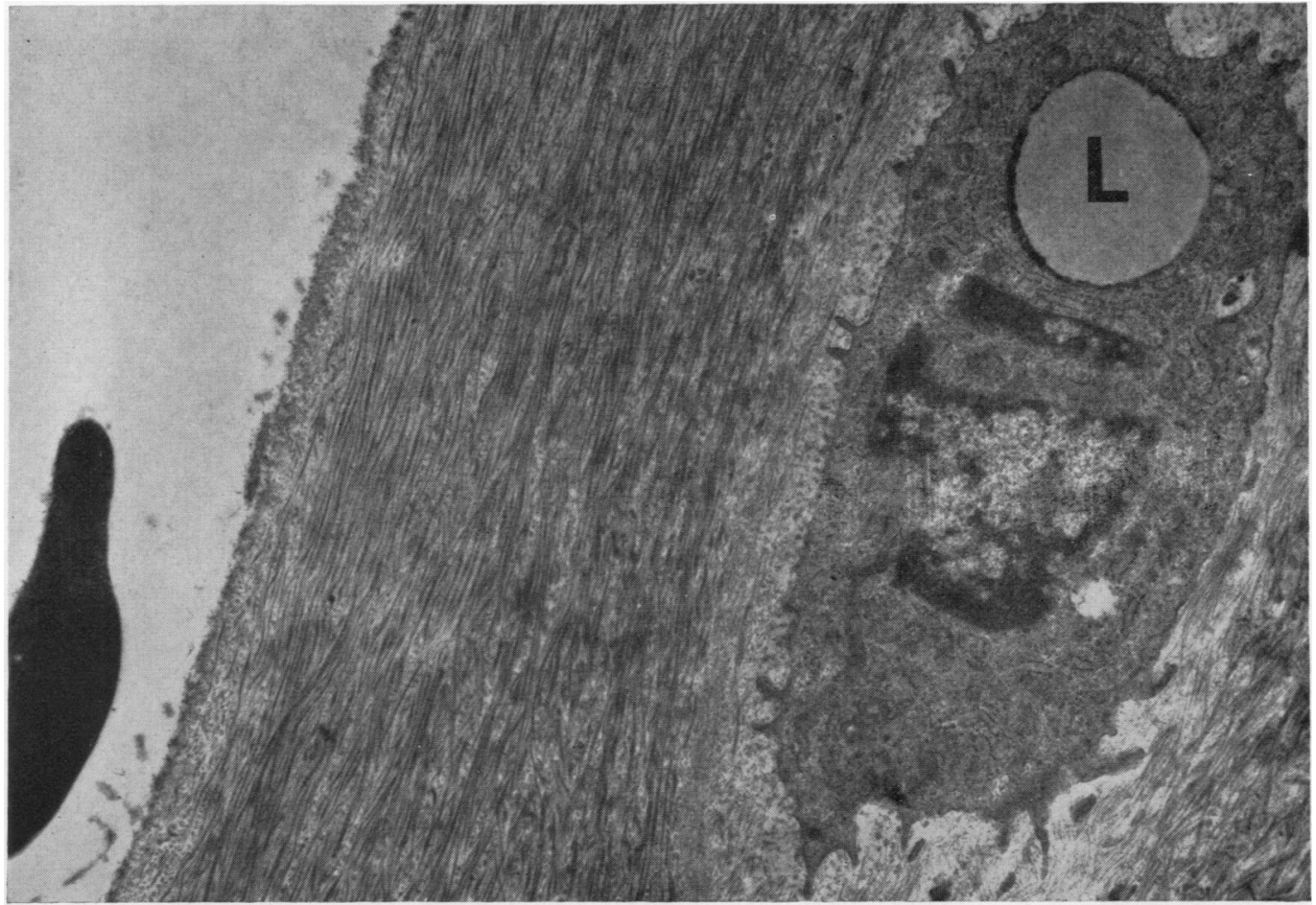

FIG. 7 Electron micrograph of control joint, showing surface of articular cartilage. An erythrocyte is seen to the extreme left. The surface is smooth. The space around the chondrocyte is narrow. The chondrocyte contains a lipid droplet $(L)$ and prominent endoplasmic reticulum. $\times 10,000$ 


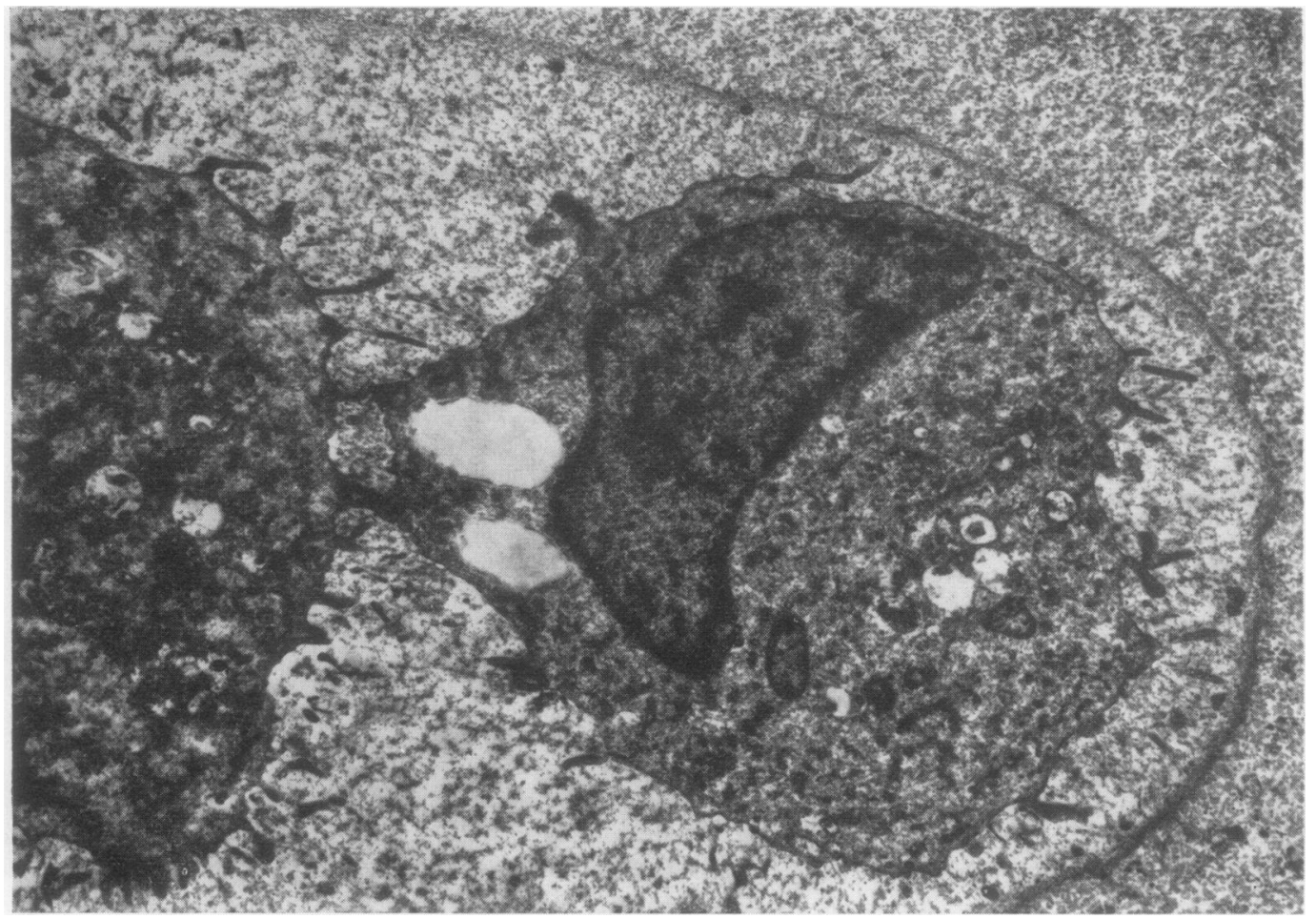

FIG. 8 Electron micrograph of articular cartilage (after nine filipin injections), showing chondrocytes surrounded by a wide moat bounded by an amorphous rim. The cytoplasm shows vacuoles and damage to mitochondria. $\times 10,000$

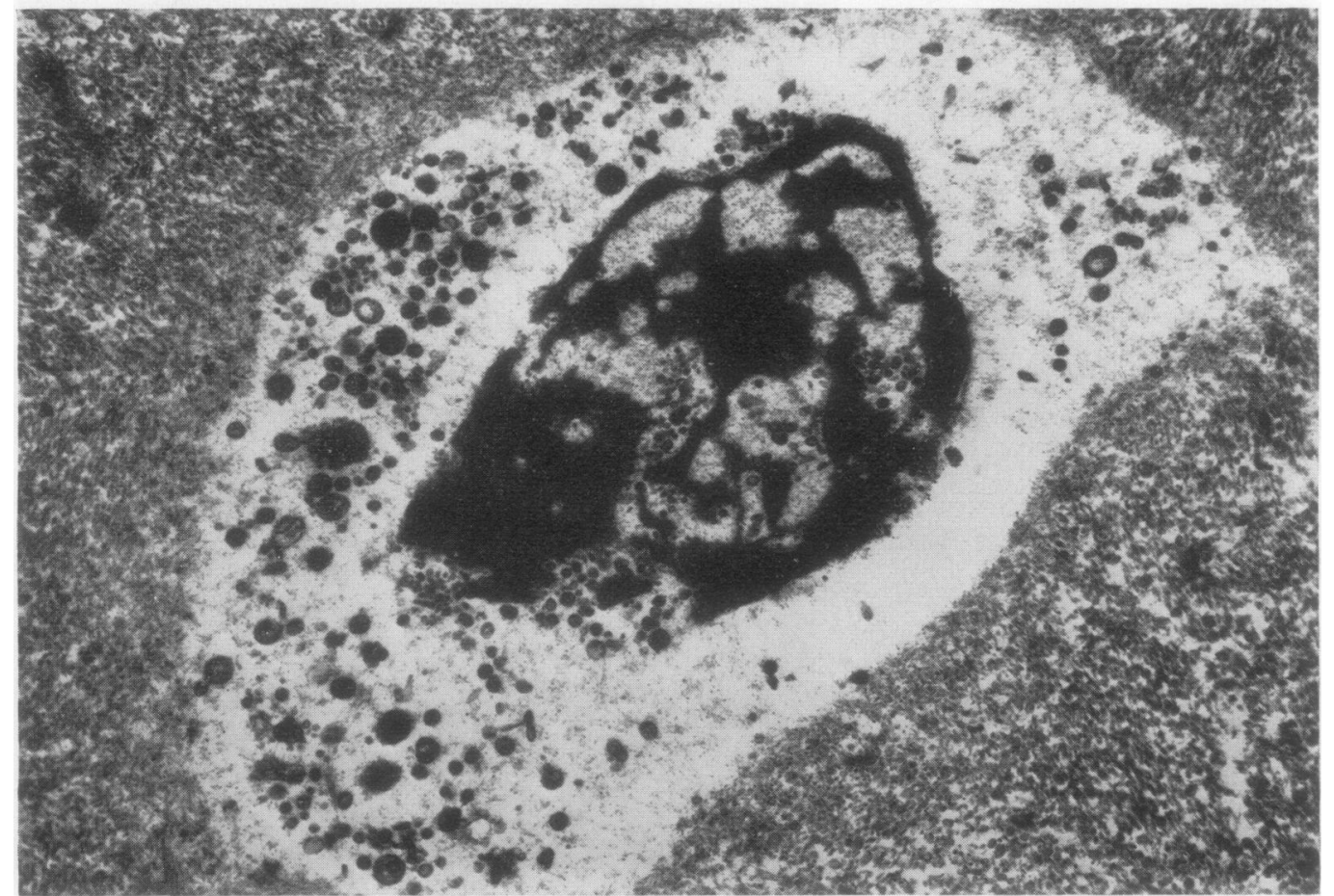

FIG. 9 Electron micrograph of articular cartilage (after nine filipin injections). The lacuna shows a disintegrating chondrocyte. $\times 12,500$ 
loss of orientation of superficial cells and fibres was noted. Chondrocytes were surrounded by wide moats containing granular or finely fibrillar material (Fig. 8). A peripheral rim of granular material bounded the lacunae. Degenerative changes were more frequent than in control cartilage and these included damage to membranes of cell organelles, accumulations of lipid, and enlarged lysosomes. Disintegrating cells were also frequent (Fig. 9). Electron dense granular droplets, possibly lipid, were present in the matrix in both control and filipin affected cartilage.

\section{Tissue enzymology}

The acid phosphatase, $\beta$-acetyl glucosaminidase, and cathepsin $D$ activities per $\mathrm{g}$. of synovial tissue in control and filipin-injected joints are shown in Table I and Fig. 10. There were significantly higher readings in the treated joints; $\mathrm{P}<\mathbf{0 . 0 0 1}$ for a ' $\mathrm{t}$ ' test on paired samples.

Table II and Fig. 11 (overleaf) show results expressed per DNA content as a measure of tissue cellularity. The differences are also significant.

In Table III and Fig. 12 (overleaf), the AGA and cathepsin D activities per $\mathrm{g}$. of articular cartilage are shown. The AGA levels were generally higher on the treated side, but the difference failed to reach statistical significance. Cathepsin D activity was, however, significantly higher on the treated side $(\mathrm{P}<\cdot 05)$.

Enzyme activities per DNA content of cartilage are shown in Fig. 13 (overleaf). Again there was a significantly higher level of cathepsin $\mathrm{D}$ in filipintreated cartilage $(P<0.025)$ and in this case for AGA $(\mathrm{P}<\cdot 02)$.

A comparison of AGA activity per $\mathrm{g}$. of synovial tissue and cartilage in the same filipin-treated joint is shown in Fig. 14 and for cathepsin D in Fig. 15 (overleaf).
It can be seen that there was no correlation. The $r$ value for the cathepsin D comparison is -0.65 which is not statistically significant, and although the numbers are small the trend is towards a negative rather than a positive correlation.

\section{Discussion}

Obtaining articular cartilage biopsies from early or only moderately advanced disease in rheumatoid patients has proved difficult and our experience is so far limited to a small number of joints. An additional reason for turning to an experimental model is that it avoids the risk of a small biopsy from unrepresentative tissue which cannot always be avoided with human material. Obtaining a suitable experimental model for rheumatoid arthritis is difficult and Gardner (1960), in an extensive review, suggested that it was only possible to obtain a superficial

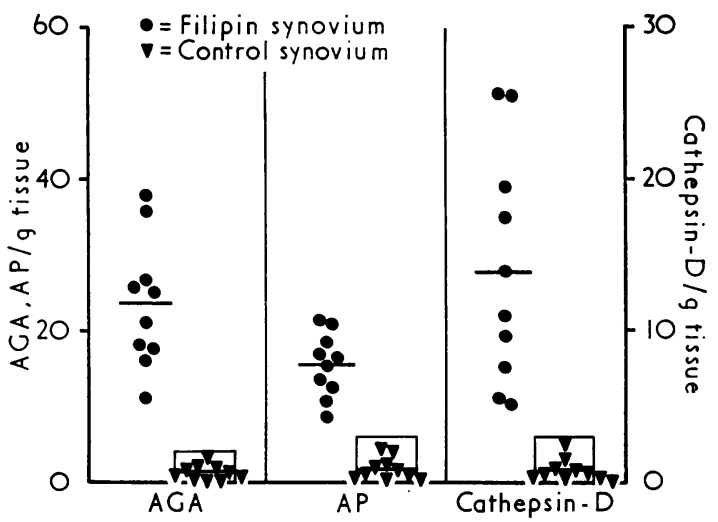

FIG. 10 Enzyme activities from homogenates of synovial membrane. Units are expressed as $\mu$ mole PNP (for AGA or AP assay) or tyrosine (for cathepsin $D$ assay) produced per hour

Table I Synovium

\begin{tabular}{|c|c|c|c|c|c|}
\hline \multicolumn{2}{|l|}{$A G A / g$} & \multicolumn{2}{|l|}{$A P / g$} & \multicolumn{2}{|c|}{ Cathepsin D/g. } \\
\hline Normal & Test & Normal & Test & Normal & Test \\
\hline $\begin{array}{l}3 \cdot 35 \\
0.83 \\
2.45 \\
2.01 \\
1.04 \\
0 \cdot 38 \\
1.84 \\
1.25 \\
0.82 \\
0 \cdot 32\end{array}$ & $\begin{array}{l}37 \cdot 62 \\
11 \cdot 04 \\
17 \cdot 75 \\
26 \cdot 58 \\
21 \cdot 07 \\
17 \cdot 68 \\
35 \cdot 37 \\
25 \cdot 73 \\
25 \cdot 37 \\
16 \cdot 03\end{array}$ & $\begin{array}{l}3.89 \\
1.11 \\
2.13 \\
4.64 \\
1.78 \\
0.79 \\
2.69 \\
1.55 \\
0.51 \\
1.12\end{array}$ & $\begin{array}{r}18 \cdot 53 \\
10.93 \\
13 \cdot 21 \\
15 \cdot 14 \\
21 \cdot 36 \\
8.95 \\
20 \cdot 74 \\
16 \cdot 11 \\
16 \cdot 60 \\
12 \cdot 46\end{array}$ & $\begin{array}{l}1.10 \\
0.30 \\
0.71 \\
0.56 \\
2.47 \\
0.47 \\
1.59 \\
0.93 \\
1.03 \\
0.44\end{array}$ & $\begin{array}{r}10 \cdot 95 \\
5 \cdot 32 \\
4 \cdot 99 \\
13 \cdot 42 \\
16 \cdot 44 \\
9 \cdot 52 \\
7 \cdot 53 \\
19 \cdot 33 \\
25 \cdot 44 \\
25 \cdot 41\end{array}$ \\
\hline$* 1.42 \pm 0.97$ & $23 \cdot 42 \pm 8.44$ & $2.02 \pm 1.35$ & $15.40 \pm 4.09$ & $0.96 \pm 0.66$ & $13 \cdot 84 \pm 7 \cdot 62$ \\
\hline $\begin{array}{c}\mathrm{T} \text { test } \\
\text { on } \\
\text { paired } \\
\text { values }\end{array}$ & 0.001 & & 001 & & .001 \\
\hline
\end{tabular}

* mean and standard deviation. 
Table II Synovium

\begin{tabular}{|c|c|c|c|c|c|}
\hline \multicolumn{2}{|c|}{$A G A / m g . D N A$} & \multicolumn{2}{|c|}{$A P / m g . D N A$} & \multicolumn{2}{|c|}{ Cathepsin D/mg.DNA } \\
\hline Normal & Test & Normal & Test & Normal & Test \\
\hline $\begin{array}{r}14.0 \\
1.9 \\
12 \cdot 1 \\
4.6 \\
5.5 \\
1.9 \\
3 \cdot 2 \\
2.3 \\
4.2 \\
0.3\end{array}$ & $\begin{array}{r}70 \cdot 0 \\
16 \cdot 7 \\
45 \cdot 6 \\
69 \cdot 9 \\
38 \cdot 0 \\
37 \cdot 7 \\
39 \cdot 4 \\
33 \cdot 1 \\
18 \cdot 5 \\
9 \cdot 4\end{array}$ & $\begin{array}{r}16.2 \\
1.4 \\
10.5 \\
10.7 \\
5.9 \\
3.9 \\
4.7 \\
2.8 \\
2.6 \\
0.9\end{array}$ & $\begin{array}{r}34 \cdot 5 \\
16 \cdot 5 \\
33 \cdot 9 \\
39 \cdot 8 \\
38 \cdot 5 \\
19 \cdot 1 \\
23 \cdot 1 \\
20 \cdot 7 \\
12 \cdot 1 \\
7 \cdot 3\end{array}$ & $\begin{array}{l}4 \cdot 57 \\
0.51 \\
3 \cdot 49 \\
1 \cdot 29 \\
8 \cdot 14 \\
2 \cdot 31 \\
2 \cdot 75 \\
1 \cdot 71 \\
5.25 \\
0 \cdot 35\end{array}$ & $\begin{array}{r}20 \cdot 38 \\
8 \cdot 05 \\
12 \cdot 82 \\
35 \cdot 28 \\
29 \cdot 60 \\
20 \cdot 28 \\
8 \cdot 39 \\
24 \cdot 89 \\
18 \cdot 54 \\
14 \cdot 87\end{array}$ \\
\hline $5.0 \pm 4 \cdot 5$ & $37 \cdot 8 \pm 20 \cdot 5$ & $6 \cdot 0 \pm 5 \cdot 0$ & $24 \cdot 6 \pm 11 \cdot 4$ & $3 \cdot 04 \pm 2 \cdot 42$ & $19 \cdot 31 \pm 8 \cdot 84$ \\
\hline \multicolumn{2}{|c|}{$\mathrm{P}<0.001$} & \multicolumn{2}{|c|}{$P<0.001$} & \multicolumn{2}{|c|}{$\mathrm{P}<0.05$} \\
\hline
\end{tabular}

Table III Cartilage

\begin{tabular}{|c|c|c|c|c|c|c|c|}
\hline \multicolumn{2}{|l|}{$A G A / g$. } & \multicolumn{2}{|c|}{ Cathepsin D/g. } & \multicolumn{2}{|c|}{$A G A / m g . D N A$} & \multicolumn{2}{|c|}{ Cathepsin D/mg.DNA } \\
\hline Normal & Test & Normal & Test & Normal & Test & Normal & Test \\
\hline $\begin{array}{l}2 \cdot 64 \\
4 \cdot 58 \\
6 \cdot 27 \\
6 \cdot 39 \\
1 \cdot 95 \\
5 \cdot 23 \\
2 \cdot 67\end{array}$ & $\begin{array}{r}4 \cdot 19 \\
3.25 \\
12.71 \\
11.47 \\
3.57 \\
2.41 \\
6.85\end{array}$ & $\begin{array}{l}1.01 \\
1.68 \\
1.86 \\
2.06 \\
0.98 \\
1.47 \\
0.32\end{array}$ & $\begin{array}{l}2.30 \\
3.70 \\
5.22 \\
2.42 \\
1.50 \\
1.53 \\
1.25\end{array}$ & $\begin{array}{l}1.99 \\
0.21 \\
0.82 \\
0.95 \\
1.00 \\
0.95 \\
1.02 \\
0.19 \\
0.40 \\
1 \cdot 12\end{array}$ & $\begin{array}{l}2 \cdot 55 \\
2 \cdot 10 \\
1 \cdot 44 \\
1 \cdot 28 \\
0 \cdot 96 \\
2 \cdot 00 \\
1 \cdot 30 \\
1 \cdot 14 \\
0 \cdot 10 \\
1 \cdot 54\end{array}$ & $\begin{array}{c}0 \cdot 223 \\
0 \cdot 182 \\
0 \cdot 365 \\
0 \cdot 367 \\
0 \cdot 282 \\
0 \cdot 329 \\
0 \cdot 114 \\
0 \cdot 133\end{array}$ & $\begin{array}{l}0.648 \\
0.423 \\
0.701 \\
1.094 \\
0.824 \\
0.275 \\
0.038 \\
0.281\end{array}$ \\
\hline $\begin{array}{l}4 \cdot 25 \pm \\
1 \cdot 83\end{array}$ & $\begin{array}{l}6 \cdot 35 \pm \\
4 \cdot 17\end{array}$ & $\begin{array}{l}1 \cdot 34 \pm \\
0 \cdot 61\end{array}$ & $\begin{array}{l}2 \cdot 56 \pm \\
1 \cdot 44\end{array}$ & $\begin{array}{l}0 \cdot 87 \pm \\
0.53\end{array}$ & $\begin{array}{l}1.44 \pm \\
0.68\end{array}$ & $\begin{array}{l}0 \cdot 249 \pm \\
0 \cdot 101\end{array}$ & $\begin{array}{l}0.536 \pm \\
0.344\end{array}$ \\
\hline \multicolumn{2}{|c|}{$P<0.20$} & \multicolumn{2}{|c|}{$P<0.05$} & & \multicolumn{2}{|c|}{$P<0.025$} \\
\hline
\end{tabular}

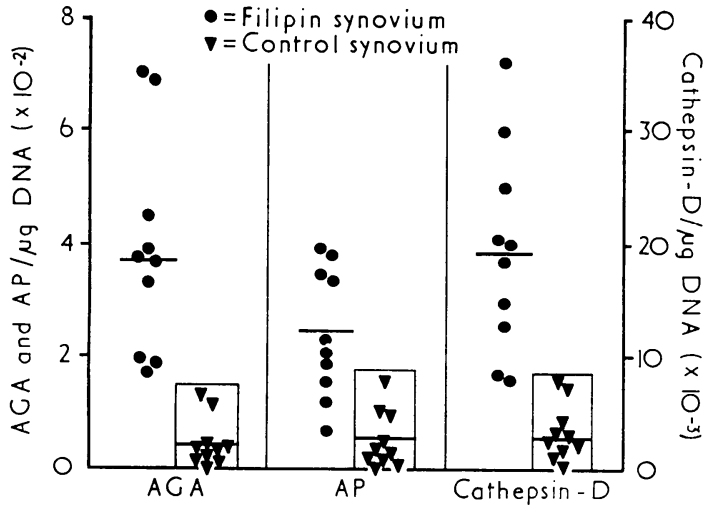

FIG. 11 As for Fig. 10, but results relate to DNA content of tissue (synovium)

resemblance to the disease in small animals. Filipin causes, in the repeatedly injected joint, a chronic arthritis with synovial lining cell proliferation and a cellular infiltrate of inflammatory cells which include plasma cells and lymphocytes. In addition, it causes

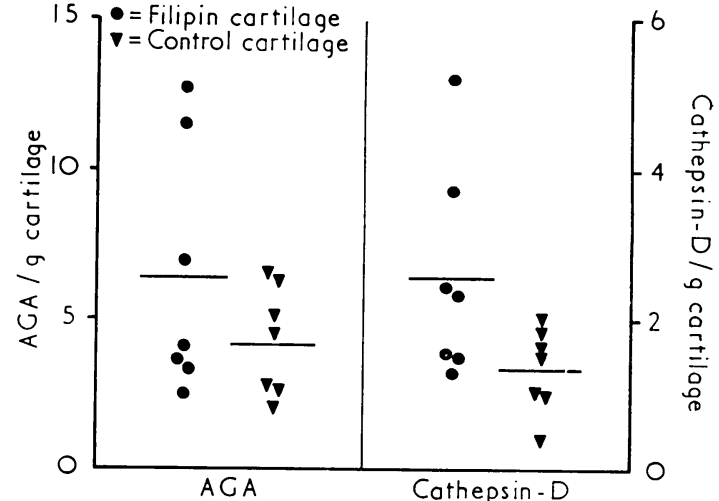

FIG. 12 Enzymes released from articular cartilage per $g$. tissue

cartilage changes and bony erosions which give it more than a superficial resemblance to rheumatoid arthritis. Weissmann and others (1967) found some similarity to osteoarthritis in the cartilage damage induced by filipin, but we have found that the 


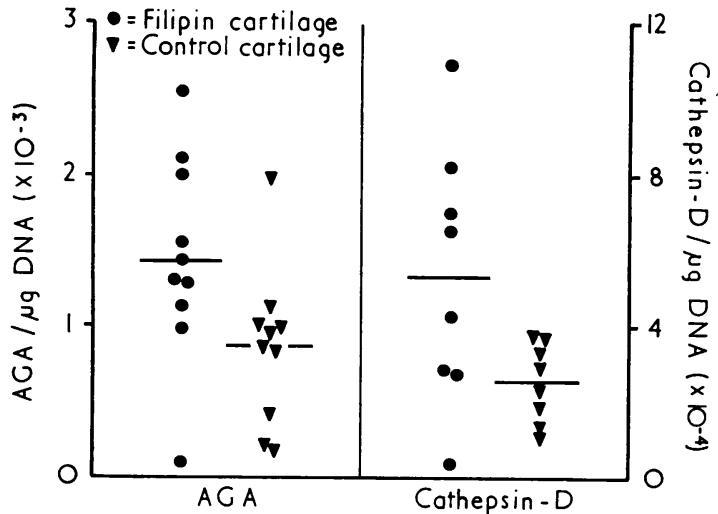

FIG. 13 Enzymes released from articular cartilage per DNA content of tissue

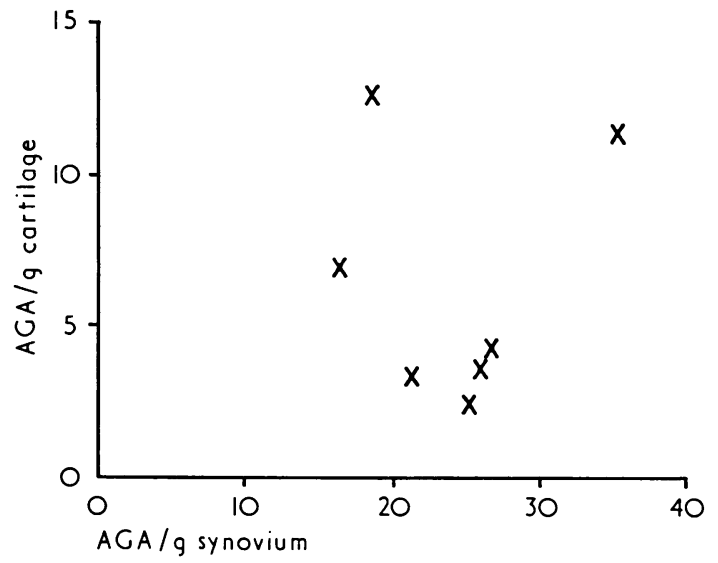

FIG. 14 Comparisons of $\beta$-acetyl glucosaminidase released per $g$. cartilage and synovium

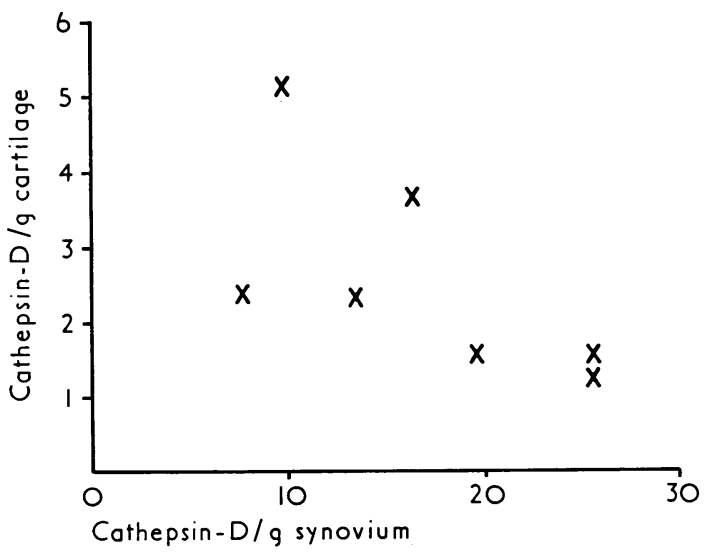

FIG. 15 Comparisons of cathepsin $D$ released per $g$. cartilage and synovium overall picture is more like that of an erosive inflammatory arthritis. The lysosomal enlargement in Type A synovial lining cells noted on electron microscopy (Fig. 5) is characteristic of rheumatoid disease (Barland, Novikoff, and Hamerman, 1964) and the ultrastructural changes in cartilage, although nonspecific, have certain features in common. The chondrocytes were often surrounded by wide moats bounded by an amorphous peripheral rim and the cytoplasmic changes of lipid accumulations, enlarged lysosomes, and evidence of degeneration are similar to those in rheumatoid arthritis (Mitchell and Shepard, 1970). It has been suggested by these authors that the moats and the material they contain represent degeneration of cartilage matrix around the cell, possibly mediated through enzymes. If so the focal nature of the changes indicates that the enzymes concerned must have arisen from the chondrocyte (see below).

A possible criticism which could be levelled at the use of a filipin-induced arthritis to study lysosomal enzyme concentrations is that this substance may act by its capacity to disrupt lysosomal membranes (Weissmann and others, 1967). The evidence for this is circumstantial and indirect and in our ultrastructural studies only a few synovial cells show marked membrane change (e.g. Fig. 6). Although dissolution of chondrocytes was seen (Fig. 9), such change was not noted in synovial cells but was sometimes seen in chondrocytes in the control cartilage. The proposed mechanism of action of filipin may in fact be relevant to the situation in rheumatoid arthritis. Weissmann (1966) has suggested that joint diseases of various aetiologies are mediated by a 'final common pathway' in which lysosomes play a major role. Such a theory requires that lysosomal membranes alter so that they either become so permeable that their contents leak out or they actively excrete their products by exocytosis. Chayen, Bitensky, Butcher, and Poulter (1969) have claimed to have demonstrated altered lysosomal membranes in rheumatoid synovial lining cells.

Whatever may be the mode of action of filipin, we have clearly shown that it causes a significant rise in the concentration of the three lysosomal enzymes measured in the synovial tissue. In articular cartilage the differences between injected and control sides were not as great for the two enzymes studied. The rise in filipin-injected joints reached statistical significance for cathepsin $D$ estimated per $g$. of cartilage, and for both AGA and cathepsin D when measured per DNA content as an expression of tissue cellularity. In most animals, the rise in cartilage enzymes was associated with a loss of metachromasia as shown by the histochemical studies with safranin 0 . This implies loss of mucopolysaccharide, such as chondroitin sulphate and keratan sulphate (Rosenberg, 1971). No attempt was made to quantitate this 
change but it is of interest that the one rabbit who showed a similar degree of safranin 0 staining on the two sides failed to show an increase in enzymes in the treated cartilage.

The capacity of lysosomal enzymes to degrade cartilage matrix is well established (see above) and Dingle (1971), using an immunoinhibition technique, has recently shown that cathepsin $D$ is the enzyme responsible for the initial breakdown. There appears to have been no previously published attempt directly to measure the activity of this important enzyme in articular cartilage either in rheumatoid arthritis or in an experimental arthritis. Demonstrating increased levels of cathepsin D and AGA in cartilage which shows histochemical and ultrastructural changes similar to rheumatoid arthritis thus adds weight to studies in vitro and other experimental studies, suggesting the role of such proteolytic enzymes in the pathogenesis of joint disease.

Experiments carried out at the Strangeways Laboratories in Cambridge and reviewed by Dingle (1969) have shown that depletion of cartilage matrix induced by excess vitamin $\mathrm{A}$ in limb-bone organ cultures was due to cathepsin derived from chondrocyte lysosomes. Page Thomas (1969) has suggested a possible active role for chondrocytes in matrix destruction in human disease. We would submit that the lack of correlation between enzyme levels in synovial membrane and cartilage indicates that the increased enzyme activity found in involved cartilage is not simply the result of diffusion of enzyme from the joint space. (According to Dingle (1971) there are no inhibitors of proteases in the synovial fluid.) The results reported in this paper indicate that at least one damaging stimulus to a joint that causes a chronic arthritis (i.e. filipin) also has a direct action on cartilage cells.

\section{Summary}

The activities of lysosomal enzymes including cathepsin $\mathbf{D}$ have been measured in homogenized articular cartilage and synovial membrane in the experimental arthritis induced by intra-articular injections of filipin in rabbits. The arthritis has histological, histochemical, and ultrastructural similarities with rheumatoid arthritis. A significant rise in cathepsin D activity was found in cartilage from injected joints compared with controls and was accompanied by a loss of safranin 0 staining, indicating depletion of mucopolysaccharide. A rise in enzyme concentration was also shown in the synovial membrane, but a correlation between the increases in synovial and cartilage enzyme activity was not demonstrated. These findings, taken together with ultrastructural evidence, show that a damaging stimulus to a joint, in this case filipin, may directly compromise the integrity of articular cartilage by leading to increased lysosomal enzyme activity within the chondrocytes.

The authors wish to thank Dr. J. R. E. Fraser for his advice and encouragement. Valuable technical assistance was provided by Mr. K. Rogers. The filipin used in the study was generously supplied by the Upjohn Company of Kalamazoo, Michigan, U.S.A.

\section{References}

Barland, P., Novikoff, A. B. and Hamerman, D. (1964) Amer. J. Path., 44, 853 (Fine structure and cytochemistry of the rheumatoid synovial membrane, with special reference to lysosomes)

Bartholomew, B. A. (1968) Univ. Mich. med. Center J., 34, 249 (Synovial fluid enzymes)

Caygill, J. C., AND Pitkeathly, D. A. (1966) Ann. rheum. Dis., 25, 137 (A study of $\beta$-acetyl-glucosaminase and acid phosphatase in pathological joint fluids)

Ceriotti, G. (1955) J. biol. Chem., 214, 59 (Determination of nucleic acids in animal tissues)

Chayen, J., Bitensky, L., Butcher, R. G. AND Poulter, L. W. (1969) Nature (Lond.), 222, 281 (Redox control of lysosomes in human synovia)

Dingle, J. T. (1962) Proc. roy. Soc. Med., 55, 109 (Lysosomal enzymes and degradation of cartilage matrix)

- (1969) In 'Lysosomes in Biology and Pathology', ed. J. T. Dingle and H. B. Fell, vol. 2, p. 421. North-Holland Publishing Co., Amsterdam (The extracellular secretion of lysosomal enzymes)

- (1971) In 'Tissue Proteinases', ed. A. J. Barrett and J. T. Dingle, p. 313. North-Holland Publishing Co., Amsterdam (The immunoinhibition of cathepsin D-mediated cartilage degradation)

Fell, H. B., AND Dingle, J. T. (1963) Biochem J., 87, 403 (Studies on the mode of action of excess of vitamin A. Lysosomal protease and the degradation of cartilage matrix)

Gardner, D. L. (1960) Ann. rheum. Dis., 19, 297 (The experimental production of arthritis: A review)

Hamerman, D., Janis, R. AND Smith, C. (1967). J. exp. Med., 126, 1005 (Cartilage matrix depletion by rheumatoid synovial cells in tissue culture).

JACOX, R. F., AND Feldman, A. (1955) J. clin. Invest., 34, 263 (Variations of $\beta$-glucuronidase in abnormal human synovial fluid)

JaNis, R., AND HAMERMAN, D. (1969) Bull. Hosp. Jt Dis., 30, 136 (Articular cartilage changes in early arthritis)

Jasani, M. K., Katori, M., AND Lewis, G. P. (1969) Ann. rheum. Dis., 28, 497 (Intracellular enzymes and kinin enzymes in synovial fluid in joint diseases)

LuscomBe, M. (1963) Nature (Lond.), 197, 1010 (Acid phosphatase and catheptic activity in rheumatoid synovial tissue) 
Mitchell, N and ShePARd, N. (1970) J. Bone Jt Surg., 52A, 1405 (The ultrastructure of articular cartilage in rheumatoid arthritis)

MuIRDEN, K. D. (1972) Ann. rheum. Dis., 31, 265 (Lysosomal enzymes in synovial membrane in rheumatoid arthritis)

Page ThOMAS, D. P. (1969) In 'Lysosomes', vol. 2, ed. J. T. Dingle and H. B. Fell, p. 87. North-Holland Publishing Co., Amsterdam (Lysosomal enzymes in experimental and rheumatoid arthritis)

Rosenberg, L. (1971) J. Bone Jt Surg., 53A, 69 (Chemical basis for the histological use of Sofranin 0 in the study of articular cartilage)

Smith, C., AND HAMERMan, D. (1962) Arthr. and Rheum., 5, 411 (Acid phosphatase in human synovial fluid)

Wegelius, O., Klockars, M. AND Vainio, U. (1968) Acta med. scand., 183, 549 (Acid phosphatase activity in rheumatoid synovia)

Weissmann, G. (1966) Arthr. and Rheum., 9, 834 (Lysosomes and joint disease)

Pras, M., AND Rosenberg, L. (1967) Ibid., 10, 325 (Arthritis induced by filipin in rabbits) AND SESSA, G. (1967) J. biol. Chem., 242, 616 (The action of polyene antibiotics on phospholipid-cholesterol structures)

WoESSNER, J. F., AND BREWER, T. H. (1963) Biochem. J., 89, 75 (Formation and breakdown of collagen and elastin in the human uterus during pregnancy and post-partum involution) 